\title{
Evo-Devo of Child Growth III: Premature Juvenility as an Evolutionary Trade-Off
}

\author{
Ze'ev Hochberg \\ Division of Pediatric Endocrinology, Meyer Children's Hospital, Rambam Medical Center, and Rappaport Family \\ Faculty of Medicine and Research Institute, Technion - Israel Institute of Technology, Haifa, Israel
}

\section{Key Words}

Juvenility $\cdot$ Adrenarche $\cdot$ Pubarche

\begin{abstract}
Juvenility was previously defined as a distinct clinical life history stage, characterized by adrenarche, decelerating growth and accelerating adiposity. This review presents the theory of evolutionary predictive adaptive strategies for premature juvenility in response to (mostly) energy supply, but also to other environmental cues. In the absence of longitudinal adrenal androgen levels, premature juvenility can be diagnosed by auxological criteria. Syndromes of short stature that are associated with premature juvenility include Prader-Willi syndrome, Silver-Russell syndrome and Noonan syndrome, and it is part of the pygmy adaptive shortness of stature. The review elucidates in evolutionary terms the association of premature juvenility with SGA and PCOS.
\end{abstract}

Copyright $\odot 2010$ S. Karger AG, Basel

Juvenility was previously defined as a distinct clinical life history stage, characterized by unique endocrine and body composition changes (adrenarche, the onset of adrenal androgen production, eruption of the first molar teeth, decelerating growth and accelerating adiposity) in relation to stage-specific social assignments and neuro- cognitive maturation [1]. Juvenility is associated with changes in social behavior and cognition, often referred to as the 5 to 7 transition $[1,2]$. The child, who up to this point has been provided with food and protection, is still under the social influence of his parents, but is now taking part in hunting, gathering and tribal/family affairs without showing signs of sexual maturation. The data and theory of evolutionary strategies for transition from one life history phase to the next was previously shown to inherently contain adaptive plasticity in the timing of such transitions, including the transition from childhood to juvenility, in order to match (mostly) energy supply, but also other environmental cues $[1,3]$.

Transition into juvenility may be defined by adrenarche, the onset of adrenal androgen production at 5-6 years, tooth eruption, growth pattern and the adiposity rebound [3]. Initial taxonomy of life history stages defined pubarche, which occurs in girls and boys after 8 and 9 years, respectively, as the onset of juvenility [4]. However, in present-day children, pubarche is a late event during juvenility and quite subjective, too. Still, it is clinically obvious, and studies of premature pubarche may shed light on the impact of early or late juvenility, and body composition and metabolic adaptation strike as its most noticeable outcomes.

Whereas pubarche is a late juvenile event and adrenarche is hard to detect, the auxological measures of

\section{KARGER}

Fax +4161306 1234 E-Mail karger@karger.ch www.karger.com

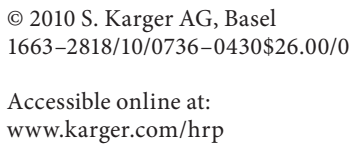

Ze'ev Hochberg, MD, $\mathrm{PhD}$

Meyer Children's Hospital, POB 9602

Haifa 31096 (Israel)

Tel. +972 4854 2157, Fax +972 48541690

E-Mail z_hochberg@rambam.health.gov.il 
juvenility onset are relatively straightforward. The juvenile growth deceleration and adiposity rebound can readily be appreciated from sequential measurements [1]. Adiposity rebound, measurable from $\Delta$-BMI, reflects a change in the nutritional status, and was shown to be an important physiological regulator of adrenarche [5]. Moreover, early adiposity rebound is associated with increased deposits of fat in juvenility, and risks associated with early rebound persist at least until early adulthood [6].

Consistent with a life history perspective, the quality of parental investment during infancy and childhood emerge as a central feature of the proximal family environment in relation to the onset of juvenility [7]. Higher quality parental investment (from both mothers and fathers) and less father-reported marital conflict or depression forecast later adrenarche.

This review presents the theory of evolutionary predictive adaptive strategies for premature juvenility in response to (mostly) energy supply, but also to other environmental cues. It takes the perspective of evolutionary fitness, defined in terms of the quantity and quality of offspring, which in turn depend on survival, body size, behavior and cognition.

\section{The Juvenile Life History Stage}

The juvenile stage, 'the age of reason and responsibility' [2], offers opportunities for the child to prepare for the social complexity of adolescence and adulthood. Occurring at the end of brain growth and equipped with the first adult molars, humans transit to juvenility when they can forage for food and take care of themselves. Whereas chimpanzees and assumingly early hominids made the move directly from infancy, Homo sapiens, who have a shorter infancy, initiate juvenility after a period of childhood $[3,8]$. Developmental psychologists refer to this period as 'middle childhood': a period of cognitively concrete operations, when children become less dependent on their parents for support and begin to interact with other adults and peers. In modern societies, the transition to juvenility may be defined by a child's readiness for school. This is associated with a systematic process of brain gray-matter reduction in the primary association areas [9], which represents synaptogenesis during this period [10].

By all 4 markers, adrenarche, molar eruption, growth deceleration and adiposity rebound, the onset of juvenility takes place at 5-6 years of age, with it happening ear- lier in girls than in boys by about 10 months and earlier in the obese than in the lean [1]. It is associated with a progressive rise in serum DHEA and DHEAS throughout juvenility [11], with effects on a wide variety of physiological systems, including the neurological and mood modulator [12, 13], the immune system [14], and somatic growth and development $[15,16]$, as reviewed [17].

In the context of early juvenility, two mechanisms, by which DHEAS may promote changes in behavior and cognition, are worth special attention [17]. One mechanism involves acting on the amygdala to reduce fearfulness and allow for the expression of an increased range of social interactions with unfamiliar individuals, as the juvenile cares for his new needs and interacts with peers. The other mechanism involves acting on the hippocampus to promote memory, social and cognitive capacity, as he joins in some more mature activities. The child with premature juvenility will undergo these changes earlier.

Juvenility and increasing adrenal androgen levels are associated with an increase in muscle mass and bone mineral content; the association of enhanced adrenal androgen generation in congenital adrenal hyperplasia with muscularity is well documented [18]. Accordingly, an increase in fat-free, lean body mass is evident around age 5 , and is greater in girls than in boys, apparently as part of the female mid-childhood spurt [19].

The close proximity of adrenarche to adiposity rebound suggests a link of transition into juvenility to energy supply [20]. It has been suggested that as brain growth tapers off during juvenility, energy allocation that was formerly associated with brain growth is temporarily stored as abdominal fat in order to support the energetically costly accelerating growth during the upcoming adolescence [17]. Indeed, the transition age to juvenility is strongly linked to the age at the onset of puberty; patients with premature puberty had early adrenarche [11], and those with delayed puberty or hypogonadotrophic hypogonadism had delayed juvenility [21].

\section{Premature Juvenility}

An early adiposity rebound has been observed in overweight children and is associated with an increased risk of overweight, suggesting that the body composition programs for transition timing from childhood to juvenility [22]. The typical pattern associated with an early adiposity rebound is a marked increase in BMI during juvenility that will exacerbate during adolescence. This pattern 


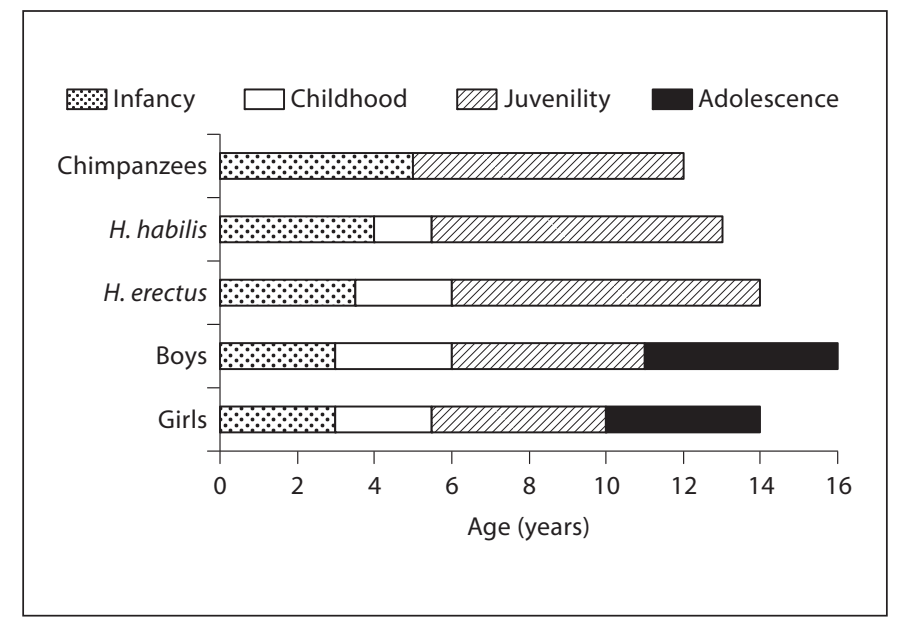

Fig. 1. Life history stages in chimpanzees, Homo habilis (1.9 mya), Homo erectus ( 0.5 mya) and Homo sapiens boys and girls, giving the average ages for transition from one stage to another. The onset of juvenility remained largely constant but its duration shortened. Adapted with permission from ADC.

has been recorded in children of recent generations as compared to those of previous generations, owing to the trend of a steeper increase of height as compared to weight in the first years of life. But even lean girls with premature adrenarche have higher levels of IGF-I, IGFBP-3 and leptin [23], mechanisms that may transmit the signal of energy readiness.

As mentioned earlier, transition to juvenility is associated with decelerating growth, and premature juvenility - with early decelerating growth - curbs the stable growth period of childhood. Thus, if all other life history stages remain unchanged, early juvenility compromises final adult height. The 10-month earlier onset of juvenility in girls also means a 10-month longer childhood of the boy. At a mean growth velocity of $7 \mathrm{~cm} /$ year for girls and $6.5 \mathrm{~cm} /$ year for boys, this delay in juvenility onset accounts for the boys' height advantage of $5.9 \mathrm{~cm}$. However, not all other life history stages remain unchanged: premature adrenarche was associated with increased childhood growth, apparently due to enhanced IGF-1 generation [24].

Several syndromes may shed further light on programming for premature juvenility. It is around the age of 3-4 that children with Prader-Willi syndrome (PWS) become progressively overweight while developing their typical high body-fat mass and low body-muscle mass [25]. Indeed, PWS patients tend to have premature and robust pubarche $[26,27]$. PWS is caused by the absence of

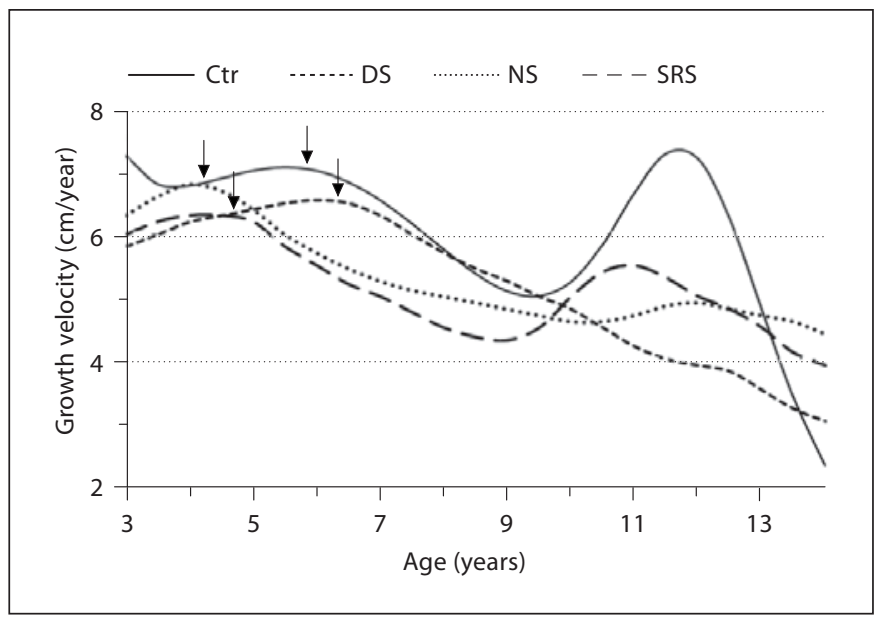

Fig. 2. Growth velocity of girls with Down syndrome (DS) [70], Noonan syndrome (NS) [31] and Silver-Russell syndrome (SRS) [29] as compared with normal girls (Ctr). The childhood-juvenility transition ages (arrows) are 6.2, 4.1 and 4.4 years, respectively, as compared with the mean normal of 5.8 years [1].

expression of genes at 15q11-q13 that are normally expressed only when paternally derived. The kinship theory predicts that children with PWS will fail to express behaviors that have increased mothers' costs of childrearing [28]. Thus, during childhood, the PWS subject has little appetite, and as they transit to early juvenility, they develop an insatiable and obsessive appetite. It is argued that the change in appetite reflects evolutionary forces associated with early transition to juvenility, when a child would begin hunting and gathering, or nowadays school, away from his mother.

Silver-Russell syndrome is caused by loss of imprinted paternal methylation at 7p13-p11.2 or 11p15 epimutation of the H19 promoter. The average girl with SilverRussell syndrome has an early juvenility at 4.4 years of age, as compared to 5.8 years in controls [29] (fig. 2). In Beckwith-Wiedemann syndrome, with the mirror mutation or deletion of imprinted genes within the chromosome 11p15.5 region, growth velocity remains above the 90 th percentile up to juvenility at $4-6$ years of age [30].

After severe intrauterine growth failure, infants and children with Noonan syndrome maintain normal growth rate along the -3.5 SDS line [31]. They show an early transition to juvenile growth (fig. 2) at 4 years of age in girls, giving them a short childhood period of only 3.2 years and a long juvenility period of 5.4 years. The short childhood and early transition to juvenility result in a 
loss of $12.2 \mathrm{~cm}$ before they reach adolescence [31]. Gainof-function mutations in the PTPN11 gene account for over half of the Noonan's patients studied. Early juvenility in this gain-of-function mutation of a protein-tyrosine phosphatase, which is known to regulate the responses of eukaryotic cells to extracellular signals [32], is intriguing.

Several studies have searched for genetic factors predisposing to premature juvenility in genes involved in steroid synthesis [33, 34], androgen action [35, 36], IGF functions [37, 38], and the Wnt signaling TCF7L2 [39]. Although some associations have been found, the underlying susceptibility genes remain largely unknown.

\section{Prenatal Growth, Premature Juvenility and PCOS}

Restricted prenatal growth was described to be associated with postnatal insulin resistance, early pubarche and exaggerated adrenarche in both boys and girls [40, 41], an observation that was not confirmed by several other studies [24, 42]. Girls, but not boys, with premature pubarche are more inclined to develop ovarian hyperandrogenism, hyperinsulinemia and dyslipidemia later in life $[43,44]$. In fact, hyperinsulinemia and dyslipidemia may be detectable as early as during juvenility, and worsen during adolescence. Low birth weight (LBW) girls with premature pubarche are known to be at particular risk of developing early menarche and hyperinsulinemic androgen excess [45-47]. Based on a cohort study of 770 children, Ong et al. [40] reported that DHEAS levels at 8 years of age were highest among LBW infants who showed rapid growth. Such children tend to gain excessive fat; their fat excess being a reflection of their hyperinsulinemia and hyperandrogenism [46]. Thus, a common sequence of events is intrauterine growth restriction, premature juvenility, hyperandrogenism, PCOS, obesity and the metabolic syndrome.

In postnatal life, the natural history of PCOS can be further modified by factors affecting insulin secretion and/or action, most importantly, nutrition. This phenomenon may be regarded as one mechanism by which nutritional cues influence reproductive development. In girls with polycystic ovaries, the physiological hyperinsulinemia of puberty may affect the genesis of both ovarian hyperandrogenemia and anovulation. Higher than normal insulin levels, whether due to a genetic predisposition or excessive weight gain (or both), would exaggerate these potentially adverse effects. Pharmacological sensitization to insulin of LBW-premature pubarche girls reduced total and visceral fat and delayed menarche without attenuating linear growth [48].

It was recently proposed that PCOS has its origin in fetal life [49]. In human females, exposure to excess androgen, at any stage from fetal development of the ovary to the onset of puberty, leads to many of the characteristic features of PCOS, including abnormalities of luteinizing hormone secretion and insulin resistance.

The association of premature juvenility, the metabolic syndrome, obesity and PCOS has been reported in unique ethnic groups, such as Caribbean Hispanic women, who are known to have an increased risk of developing both premature adrenarche and polycystic ovarian syndrome (http://pediatrics.aappublications.org/cgi/content/ full/102/3/e36) [50, 51]. It may constitute a genetic syndrome, yet, unambiguous gene mutations currently remain undetected, and I argue that it may well represent developmental programming or an adaptive response within our adaptive phenotypic plasticity, which may transmit transgenerations. Thus, the mechanism may relate to epigenetic changes rather than to the evolution of gene sequence. This is supported by the fact that premature juvenility is less common in boys as compared to girls, whose evolutionary fitness is under greater pressure. A study of androgen receptor genotype and X chromosome methylation found a smaller biallelic mean of CAG repeats in association with increased odds of PCOS [52]. The chromosome bearing the shorter CAG allele was preferentially active in PCOS women. In some women, such heightened sensitivity may also result from preferential expression of androgen receptors with shorter alleles.

\section{The Pygmy Paradigm for Premature Juvenility}

Human pygmies are defined as populations having an average male height of $155 \mathrm{~cm}$, and populations exhibiting pygmy stature reside in Africa, the Andaman Islands, Malaysia, Thailand, Indonesia, the Philippines, Papua New Guinea, Brazil and Bolivia. The small body size of human pygmies has been interpreted as adaptive to living in dense tropical forests, thermoregulation or endurance against starvation in low productivity environments [53].

Migliano et al. [53] constructed growth curves for the Philippine Aeta pygmy and compared them with the lower percentiles of the US growth distribution, representing undernourished individuals who grow only to average adult pygmy size (corresponding to the 0.01th percentile of the US distribution). The curves show that 
pygmies deviate from the US undernourished sample with an early juvenile deceleration, early pubertal spurt and early growth cessation as compared to the US 0.01th percentile [53]. In this population with a life expectancy at birth of 16 years and a life expectancy at adulthood of 27 years, their first reproduction is between the ages of 10-14 years and last reproduction averages 37 years, but only $13-31 \%$ of pygmy women reached the end of the reproductive age.

According to life history theory, age at first reproduction is set by natural selection as the result of two opposite strategies [54]. Extended growth and large body size prompt fertility gains and reduced offspring mortality, implying a pressure for delayed reproductive onset, whereas early reproduction minimizes the likelihood of death before reproduction. Modeling fitness as a function of growth, fertility and mortality schedules, they argued that rather than through positive selection for small stature, the short stature of pygmies is a by-product of selection for early onset of reproduction. Human pygmy populations and adaptations evolved as the result of a life history tradeoff between the fitness benefits of larger body size against the costs of early juvenility, puberty and growth cessation, under circumstances of significant young and adult mortality [53].

\section{Evolutionary Perspective in Premature Juvenility}

The age at transition to juvenility has been remarkably constant throughout human evolution, especially when compared to such life-history variables as age of sexual maturation, which is subject to a wide degree of plasticity over a relatively short period of time [3]. Comparison with the African apes (but no other primates) suggests that the timing of adrenarche and the sex difference in chimpanzees out of their infancy may be similar to that in humans out of their childhood [55], though the full course of age-related changes in DHEAS and their relationship to reproductive and brain maturation are not clear [17]. The syndromic premature juvenility discussed above, and the variability in the age of adiposity rebound, imply an adaptive plasticity of no more than 2 years between early and late transition [56]. Assuming an important role for adrenarche in human brain maturation, Campbell [17] argued that the increased brain size and extended life span of humans relative to the great apes imply changes in the timing and impact of adrenarche. Thus, he argues that increases in body size evident among Homo erectus imply increases in life span and delayed re- productive maturation, and as such are a natural point at which to start a consideration of the potential role of adrenarche in human evolution [17].

The transition from childhood to juvenility is closely associated with the first permanent molar teeth eruption [4]. A comparative study across 21 primate species found the age of first molar eruption to be highly associated with brain weight $(r=0.98)$ and a host of other life history variables [57]. Data for dental eruption in 1837 showed similar eruption ages to those known today [58]: at a time of a marked worldwide upward trend for height and early sexual maturation, transition into juvenility has not changed much over the last 170 years [59]. The transition age to juvenility as determined by the eruption of the first molar may be even longer standing. A study of an early modern human from Jebel Irhoud in Morocco, dated to 160,000 years before the present, showed that the age of tooth eruption was much the same as it is today [60], suggesting that transition age to juvenility has not changed throughout the roughly 200,000 years of modern humans. The Neanderthals' permanent molars also erupted at an equivalent age of 6.5 years [61], marking the transition age to juvenility of this species.

The adaptive trade-off package includes high levels of circulating androgens in women, obesity and insulin resistance. But how can the fertility-limiting obesity and PCOS be attributed to evolutionary fitness? Corbett et al. [62] argue that PCOS, type 2 diabetes and the metabolic syndrome are modern phenotypic expressions of a metabolic genotype attuned to the dietary and energetic conditions of the pre-agrarian meat-based, high protein, low carbohydrate diet, with a genotype adjusted for protein and gluconeogenesis as metabolic fuel, through insulin resistance. They further argued that this metabolic 'fertility first' rather than 'thrifty' genotype persisted at a high prevalence throughout the entire agrarian period from around 12,000 years ago until $\sim 1800$ AD because it conferred a fertility advantage in an environment defined by chronic and often severe seasonal food shortages. Conversely, they argue that genetic adaptations to a high carbohydrate, low protein agrarian diet, with increased sensitivity to insulin action, were constrained because these adaptations compromised fertility by raising the lower bound of body weight and energy intake optimal for ovulation and reproduction.

After $\sim 1800$, the progressive attainment of dietary energy sufficiency released human populations from this constraint. This release, through the powerful mechanism of fertility selection, rapidly increased the prevalence of a genotype better suited to carbohydrate metabo- 
lism. Whereas hyperandrogenism compromises fertility, masculinization of girls and women may be a valuable trade-off for the individual, her direct family and the social group under certain environmental constraints. Androgenic activity may confer a survival advantage during life-threatening hazards [63], and fat accumulation may confer a survival advantage during periods of undernutrition.

Early adolescence, early menarche and short stature, as reported for premature pubarche [47], will be other trade-offs for this package. Likewise, Palmert et al. [11] found that among 14 girls with idiopathic premature puberty whose gonadal hormone production was suppressed by drugs, adrenarche started at age 3 and could be described from that point on as exponential. Indeed, insecure energy provision has been shown to result in short stature, as discussed above for pygmy populations, and reported for delayed infancy to childhood transition [54], traded against the advantages of large body size. Early menarche is therefore a trade-off of current reproduction against later under-fertility.

Early infancy and childhood growth are also strong predictors of juvenility. Allowing for current weight, infants who showed rapid postnatal weight gain between 0 and 3 years had higher DHEAS and androstenedione levels at age 8 [40]. Thus, juvenility onset and adrenal androgen secretion are programmed during fetal and early postnatal development, and early weight gain might therefore represent an additional mechanism that contributes to the association between LBW and hyperandrogenism.

An additional trade-off may relate to the neurological effects of DHEA, as it rises with the onset of juvenility. The social function of the juvenile, as he gains new assignments, requires the androgenic, but also synaptogenic, and mood effects of DHEA. In fact, DHEAS levels positively correlate with ratings of aggression and delinquency among juvenile boys [64], and girls with premature adrenarche show higher levels of anxiety associated with increased DHEAS levels [65]. Among women with adrenal insufficiency, DHEA supplementation improved self-esteem, sexuality and overall well-being, and decreased depression and anxiety $[12,66]$, traits that are consistent with the newly assigned social role of the juvenile.

The age of transition into juvenility is not of any major importance for the determination of final height $[67,68]$, although it is associated with distinct milestones in child growth and body proportions.

Premature Juvenility as an Evolutionary Trade-Off

\section{Conclusions: When the Package Disintegrates}

This review has been an attempt to use the life history theory in understanding premature juvenility in a broad evolutionary perspective. Life history traits respond to environmental cues in order to enhance fecundity-survival schedules and behavioral strategies that yield the highest fitness in a given environment. The transition from childhood to juvenility is part of a strategy in the transition from a period of total dependence on the family and tribe for provision and security into self-supply; it is assigned with a predictive adaptive response of body composition and energy metabolism. The transition from juvenility to adolescence is assigned with the age and length of fecundity. It entails plasticity in adapting to energy resources, other environmental cues, the social needs of adolescence and their maturation to determine fitness directly. These periods influence each other in an intricate web of connections that are related to evolutionary fitness and lifelong advantages. The data presented argue that juvenility is endowed with a programming/predictive adaptive response for a thrifty phenotype, metabolism and body composition.

In a stable environment, evolutionary pressures operate to select traits that match the organism to its environment. It seems probable that the timing of adrenarche, growth deceleration and adiposity rebound would be linked to social maturation associated with preparation for the next life history stage - adolescence. This synchrony would have been selected because the energy-consuming brain would have reached both its quasi-final size and maturation, and energy stores for future energy-consuming adolescent growth spurt would have been on hand. To prevent social competition, it would be disadvantageous for growth to precede the capacity for sexual maturation.

Gluckman and Hanson [69] proposed that human females evolved to enter puberty at a relatively young age and progressed to reproductive competence at 11-13 years of age. They argue that this would have matched the degree of psychosocial maturation necessary to function as an adult in Paleolithic hunter-gatherer society. Juvenile training for adolescence would accordingly take place between the ages 6-11. Over the following agrarian period and modern civilization, they argue, biological puberty in females has significantly preceded, rather than being matched to, the age of successful functioning as an adult.

The overweight and obesity that characterize modern society result in early adiposity rebound $[1,56]$. With weight being the major signal for biological juvenility, 
growth deceleration and adrenarche follow suit, as evident from studies in the LBW - premature pubarche PCOS complex. What does not change is the social role expected from the juvenile as he leaves the security of home and family, and engages in wider social interactions, such as school. This mismatch between the age of adolescent biological and psychosocial maturation, which has only appeared in the past 100 years, has created fundamental pressures on contemporary adolescents and on how they live in society [69]. We have not yet seen how disintegration of juvenility affects modern children.

\section{References}

$\checkmark 1$ Hochberg Z: Juvenility in the context of life history theory. Arch Dis Child 2008;93:534539.

2 White S: The child's entry into the age of reason; in Sameroff A, Haith MM (ed): The Five to Seven Year Shift: The Age of Reason and Responsibility. Chicago, University of Chicago Press, 1996, pp 17-32.

-3 Hochberg Z: Evo-devo of child growth II: Human life history and transition between its phases. Eur J Endocrinol 2009;160:135141.

4 Bogin B: Evolutionary perspective on human growth. Annu Rev Anthropol 1999;28:109153.

5 Remer T, Manz F: Role of nutritional status in the regulation of adrenarche. J Clin Endocrinol Metab 1999;84:3936-3944.

6 Williams SM, Goulding A: Patterns of growth associated with the timing of adiposity rebound. Obesity (Silver Spring) 2009;17: 335-341.

7 Ellis BJ, Essex MJ: Family environments, adrenarche, and sexual maturation: a longitudinal test of a life history model. Child Dev 2007:78:1799-1817.

-8 Smith BH, Tompkins RL: Toward a life history of the hominidae. Annu Rev Anthropol 1995;24:257-279.

$\checkmark 9$ Gogtay N, Giedd JN, Lusk L, Hayashi KM, Greenstein D, Vaituzis AC, Nugent TF 3rd, Herman DH, Clasen LS, Toga AW, Rapoport JL, Thompson PM: Dynamic mapping of human cortical development during childhood through early adulthood. Proc Natl Acad Sci USA 2004; 101:8174-8179.

10 Paus T: Mapping brain maturation and cognitive development during adolescence. Trends Cogn Sci 2005;9:60-68.

- 11 Palmert MR, Hayden DL, Mansfield MJ, Crigler JF Jr, Crowley WF Jr, Chandler DW, Boepple PA: The longitudinal study of adrenal maturation during gonadal suppression: evidence that adrenarche is a gradual process. J Clin Endocrinol Metab 2001;86:4536-4542.

-12 Hunt PJ, Gurnell EM, Huppert FA, Richards C, Prevost AT, Wass JA, Herbert J, Chatterjee VK: Improvement in mood and fatigue after dehydroepiandrosterone replacement in Addison's disease in a randomized, double blind trial. J Clin Endocrinol Metab 2000; 85:4650-4656.
13 Suzuki T, Sasano H, Takeyama J, Kaneko C Freije WA, Carr BR, Rainey WE: Developmental changes in steroidogenic enzymes in human postnatal adrenal cortex: immunohistochemical studies. Clin Endocrinol (Oxf) 2000;53:739-747.

14 Chen CC, Parker CR Jr: Adrenal androgens and the immune system. Semin Reprod Med 2004;22:369-377.

15 Arquitt AB, Stoecker BJ, Hermann JS, Winterfeldt EA: Dehydroepiandrosterone sulfate, cholesterol, hemoglobin, and anthropometric measures related to growth in male adolescents. J Am Diet Assoc 1991;91:575579.

16 Zemel BS, Katz SH: The contribution of adrenal and gonadal androgens to the growth in height of adolescent males. Am J Phys Anthropol 1986;71:459-466.

17 Campbell B: Adrenarche and the evolution of human life history. Am J Hum Biol 2006; 18:569-589.

18 Rodda C, Jones DA, Round J, Grant DB: Muscle strength in girls with congenital adrenal hyperplasia. Acta Paediatr Scand 1987; 76:495-499.

19 Ellis KJ: Body composition of a young, multiethnic, male population. Am J Clin Nutr 1997;66:1323-1331.

20 Remer T, Manz F: The midgrowth spurt in healthy children is not caused by adrenarche. J Clin Endocrinol Metab 2001;86:4183-4186.

21 Van Dop C, Burstein S, Conte FA, Grumbach MM: Isolated gonadotropin deficiency in boys: clinical characteristics and growth. J Pediatr 1987;111:684-692.

22 Rolland-Cachera MF, Deheeger M, Maillot M, Bellisle F: Early adiposity rebound: causes and consequences for obesity in children and adults. Int J Obes (Lond) 2006;30(Suppl 4):S11-S17.

23 Guven A, Cinaz P, Ayvali E: Are growth factors and leptin involved in the pathogenesis of premature adrenarche in girls? J Pediatr Endocrinol Metab 2005;18:785-791.

24 Utriainen P, Voutilainen R, Jaaskelainen J: Girls with premature adrenarche have accelerated early childhood growth. J Pediatr 2009;154:882-887.
25 Lindgren AC, Barkeling B, Hagg A, Ritzen EM, Marcus C, Rossner S: Eating behavior in Prader-Willi syndrome, normal weight, and obese control groups. J Pediatr 2000;137:5055.

26 Hirsch HJ, Eldar-Geva T, Benarroch F, Rubinstein O, Gross-Tsur V: Primary testicular dysfunction is a major contributor to abnormal pubertal development in males with Prader-Willi syndrome. J Clin Endocrinol Metab 2009;94:2262-2268.

-27 Unanue N, Bazaes R, Iniguez G, Cortes F, Avila A, Mericq V: Adrenarche in PraderWilli syndrome appears not related to insulin sensitivity and serum adiponectin. Horm Res 2007;67:152-158.

28 Haig D, Wharton R: Prader-Willi syndrome and the evolution of human childhood. Am J Hum Biol 2003; 15:320-329.

29 Wollmann HA, Kirchner T, Enders H, Preece MA, Ranke MB: Growth and symptoms in Silver-Russell syndrome: review on the basis of 386 patients. Eur J Pediatr 1995; 154:958-968.

30 Sippell WG, Partsch CJ, Wiedemann HR: Growth, bone maturation and pubertal development in children with the EMG-syndrome. Clin Genet 1989;35:20-28.

- 31 Ranke MB, Heidemann P, Knupfer C, Enders $\mathrm{H}$, Schmaltz AA, Bierich JR: Noonan syndrome: growth and clinical manifestations in 144 cases. Eur J Pediatr 1988;148:220-227.

32 Dechert U, Duncan AM, Bastien L, Duff C, Adam M, Jirik FR: Protein-tyrosine phosphatase SH-PTP2 (PTPN11) is localized to 12q24.1-24.3. Hum Genet 1995;96:609-615.

33 Witchel SF, Smith R, Tomboc M, Aston CE: Candidate gene analysis in premature pubarche and adolescent hyperandrogenism. Fertil Steril 2001;75:724-730.

- 34 Petry CJ, Ong KK, Michelmore KF, Artigas $\mathrm{S}$, Wingate DL, Balen $\mathrm{AH}$, de Zegher $\mathrm{F}$, Ibanez L, Dunger DB: Association of aromatase (CYP 19) gene variation with features of hyperandrogenism in two populations of young women. Hum Reprod 2005;20:18371843

35 Ibanez L, Ong KK, Mongan N, Jaaskelainen J, Marcos MV, Hughes IA, De Zegher F, Dunger DB: Androgen receptor gene CAG repeat polymorphism in the development of ovarian hyperandrogenism. J Clin Endocrinol Metab 2003;88:3333-3338. 
36 Lappalainen S, Utriainen P, Kuulasmaa T, Voutilainen R, Jaaskelainen J: Androgen receptor gene CAG repeat polymorphism and $\mathrm{X}$-chromosome inactivation in children with premature adrenarche. J Clin Endocrinol Metab 2008;93:1304-1309.

-37 Ibanez L, Ong K, Potau N, Marcos MV, de Zegher F, Dunger D: Insulin gene variable number of tandem repeat genotype and the low birth weight, precocious pubarche, and hyperinsulinism sequence. J Clin Endocrinol Metab 2001;86:5788-5793.

-38 Roldan MB, White C, Witchel SF: Association of the GAA1013->GAG polymorphism of the insulin-like growth factor-1 receptor (IGF1R) gene with premature pubarche. Fertil Steril 2007;88:410-417.

-39 Lappalainen S, Voutilainen R, Utriainen P, Laakso M, Jaaskelainen J: Genetic variation of FTO and TCF712 in premature adrenarche. Metabolism 2009;58:1263-1269.

-40 Ong KK, Potau N, Petry CJ, Jones R, Ness AR, Honour JW, de Zegher F, Ibanez L, Dunger DB: Opposing influences of prenatal and postnatal weight gain on adrenarche in normal boys and girls. J Clin Endocrinol Metab 2004;89:2647-2651.

-41 Dahlgren J, Boguszewski M, Rosberg S, Albertsson-Wikland K: Adrenal steroid hormones in short children born small for gestational age. Clin Endocrinol (Oxf) 1998;49: 353-361.

42 Hokken-Koelega AC: Timing of puberty and fetal growth. Best Pract Res Clin Endocrinol Metab 2002;16:65-71.

43 Potau N, Ibanez L, Rique S, Sanchez-Ufarte $\mathrm{C}$, de Zegher F: Pronounced adrenarche and precocious pubarche in boys. Horm Res 1999;51:238-241.

-44 Ibanez L, Dimartino-Nardi J, Potau N, Saenger P: Premature adrenarche - normal variant or forerunner of adult disease? Endocr Rev 2000;21:671-696.

45 Ibanez L, Potau N, Francois I, de Zegher F: Precocious pubarche, hyperinsulinism, and ovarian hyperandrogenism in girls: relation to reduced fetal growth. J Clin Endocrinol Metab 1998;83:3558-3562.

46 Ibanez L, Ong K, de Zegher F, Marcos MV, del Rio L, Dunger DB: Fat distribution in non-obese girls with and without precocious pubarche: central adiposity related to insulinaemia and androgenaemia from prepuberty to postmenarche. Clin Endocrinol (Oxf) 2003;58:372-379.
7 Ibanez L, Jimenez R, de Zegher F: Early puberty-menarche after precocious pubarche: relation to prenatal growth. Pediatrics 2006; 117:117-121.

48 Ibanez L, Lopez-Bermejo A, Diaz M, Marcos MV, de Zegher F: Metformin treatment for four years to reduce total and visceral fat in low birth weight girls with precocious pubarche. J Clin Endocrinol Metab 2008;93: 1841-1845.

49 Franks S, McCarthy MI, Hardy K: Development of polycystic ovary syndrome: Involvement of genetic and environmental factors. Int J Androl 2006;29:278-285, discussion 286-290.

-50 Banerjee S, Raghavan S, Wasserman EJ, Linder BL, Saenger P, DiMartino-Nardi J: Hormonal findings in African-American and Caribbean Hispanic girls with premature adrenarche: implications for polycystic ovarian syndrome. Pediatrics 1998;102:E36.

51 Dunaif A, Sorbara L, Delson R, Green G: Ethnicity and polycystic ovary syndrome are associated with independent and additive decreases in insulin action in CaribbeanHispanic women. Diabetes 1993;42:14621468

52 Shah NA, Antoine HJ, Pall M, Taylor KD, Azziz R, Goodarzi MO: Association of androgen receptor CAG repeat polymorphism and polycystic ovary syndrome. J Clin Endocrinol Metab 2008;93:1939-1945.

53 Migliano AB, Vinicius L, Lahr MM: Life history trade-offs explain the evolution of human pygmies. Proc Natl Acad Sci USA 2007; 104:20216-20219.

54 Hochberg Z, Albertsson-Wikland K: Evodevo of infantile and childhood growth. Pediatr Res 2008;64:2-7.

55 Cutler GB Jr, Glenn M, Bush M, Hodgen GD Graham CE, Loriaux DL: Adrenarche: a survey of rodents, domestic animals, and primates. Endocrinology 1978;103:2112-2118.

56 Cole TJ, Freeman JV, Preece MA: Body mass index reference curves for the UK, 1990. Arch Dis Child 1995;73:25-29.

57 Smith BH: Patterns of dental development in Homo, Australopithecus, Pan, and Gorilla. Am J Phys Anthropol 1994;94:307-325.

58 Saunders E: Teeth a test of age. London, Renshaw, 1837.
59 Helm S: Secular trend in tooth eruption: a comparative study of Danish school children of 1913 and 1965. Arch Oral Biol 1969;14: 1177-1191.

60 Smith TM, Tafforeau P, Reid DJ, Grun R, Eggins S, Boutakiout M, Hublin JJ: From the cover: earliest evidence of modern human life history in North African early Homo sapiens. Proc Natl Acad Sci USA 2007;104: 6128-6133.

61 Coppa A, Manni F, Stringer C, Vargiu R, Vecchi F: Evidence for new Neanderthal teeth in Tabun cave (Israel) by the application of self-organizing maps (SOMs). J Hum Evol 2007;52:601-613.

62 Corbett SJ, McMichael AJ, Prentice AM: Type 2 diabetes, cardiovascular disease, and the evolutionary paradox of the polycystic ovary syndrome: a fertility first hypothesis. Am J Hum Biol 2009;21:587-598.

63 Hochberg Z, Etzioni A: Genetic selection in nonclassical adrenal hyperplasia. J Clin Endocrinol Metab 1995;80:325-326.

64 van Goozen SH, Matthys W, Cohen-Kettenis PT, Thijssen JH, van Engeland H: Adrenal androgens and aggression in conduct disorder prepubertal boys and normal controls. Biol Psychiatry 1998;43:156-158.

65 Dorn LD, Hitt SF, Rotenstein D: Biopsychological and cognitive differences in children with premature vs. on-time adrenarche. Arch Pediatr Adolesc Med 1999;153:137146.

66 Arlt W, Callies F, Allolio B: DHEA replacement in women with adrenal insufficiency - pharmacokinetics, bioconversion and clinical effects on well-being, sexuality and cognition. Endocr Res 2000;26:505-511.

67 Ibanez L, Virdis R, Potau N, Zampolli M, Ghizzoni L, Albisu MA, Carrascosa A, Bernasconi S, Vicens-Calvet E: Natural history of premature pubarche: an auxological study. J Clin Endocrinol Metab 1992;74:254-257.

68 Pere A, Perheentupa J, Peter M, Voutilainen $\mathrm{R}$ : Follow up of growth and steroids in premature adrenarche. Eur J Pediatr 1995;154: 346-352.

-69 Gluckman PD, Hanson MA: Evolution, development and timing of puberty. Trends Endocrinol Metab 2006;17:7-12.

70 Cronk C, Crocker AC, Pueschel SM, Shea AM, Zackai E, Pickens G, Reed RB: Growth charts for children with down syndrome: 1 month to 18 years of age. Pediatrics $1988 ; 81$ : 102-110. 